\title{
Women, Men and Education in Azerbaijan
}

\author{
Kifayat Aghayeva \\ Azerbaijan University of Languages, \\ Baku, Azerbaijan \\ Promoting of gender equality in science is a vital part of the European Union's \\ research policy \\ (Phillipe Busquin, 2004).
}

\section{The History of Gender Studies in Azerbaijan}

Civilization has entered into the third millennium of a new era. However, ever since the last centuries of the second millennium, it has been facing a mass of issues related to inequality of the sexes, which found their reflection in both the dynamics of the social struggles marking those centuries - feminist movements, as well as in various fields of the spiritual culture of these centuries - in sociopolitical thought, in literature, mass media, etc. The XX-XXI centuries became a time marked by the emergence of the struggle for gender equality as one of the priority directions of both global politics and global science. The problems of relations between the sexes, known as "gender relations" in modern science, which include the sexes' inequality issues, became one of the most important targets of the politicians, ideologues and scientists of the "new world" - the world which merged socialist and capitalist sides.

The "transition period" displayed in all areas of the social-cultural life (science and education included) of the Azerbaijan society with its positive and negative facets. As a result, first, Women's Studies, then Gender Studies appeared as social needs of the society.

In Azerbaijan the process of institutionalization of Gender Studies starts approximately in the 1990s, when "gender," "gender studies", "gender approach", 
"gender roles" and other gender-related terms were used in the public discourse although social research of sex was studied in the Soviet times. During the last two decades essential development has happened in the field of Gender Studies. Today the geography and frame of gender research is wider. Different scientific gender related journals articles, books, and manuals are published in Azerbaijan. Various fields of Gender Studies are studied and taught in universities of the country.

This development may be conditionally divided into four stages:

1. Organizational stage of enlightenment, applying new scientific paradigm (19931994);

2. Institutionalization stage of research (1994-1995), increasing numbers of gender centers and official registration of scientific organizations;

3. Creation of expert teachers of Gender Studies (1997-1999);

4. Stage of activating work toward legitimating and expanding Gender Studies (1999 up today);

Taking into consideration changing status of different social groups and people's categories and very important social-cultural and political changes in the Azerbaijan society during the last decades consequently, the changes in the sphere of gender become apparent. These changes lead to the changes in the structure of the family, changes in the social guarantees, and changes of women's positions in the economical and political sphere. These events frequently trigger the feminization of unemployment and poverty, age and sex discrimination (it is not uncommon while applying for a job), spreading violence, women trafficking, sexual exploitation etc. Real gender inequity problems in the public discourse lead to the increase of scientific research and public interest in this subject.

The importance of the intellectual-cultural climate in the contemporary Azerbaijani society draws attention towards a postmodernist and post-structural paradigm. Modern feministic critics are an integral part of the postmodernist discourse which contributes to the development of gender theory in the Azerbaijan context.

As mentioned above, Azerbaijan Gender Studies started in the 1990s. The main issue influencing this factor is the development of the women's movement in Azerbaijan. The women's movement has never been massive and politically powerful, but this movement triggered the infrastructure of intellectual interchange and contributed to formulating the network of researchers and activists who were interested in the elaboration of this subject. The women's movement influenced the feminist enlightenment, promoting the carrying out of research projects and formulating associations. (It would be interesting to include the infrastructure of Azerbaijan and European women's movements as a research source). 
Among the main factors promoting the development of Gender Studies is the globalization factor, hence, Azerbaijan Women's organizations and centers have many international contacts. These centers were formulated as a result of the second women's movements of the USA and Western Europe. Today's political atmosphere allows Azerbaijani researchers participate in international projects and conferences, to exchange expertise and publish their works abroad. This interconnection gives them access to professional literature, benefit from the experience of joint research and discussion, and financing possibilities.

Interest in Gender Studies is interconnected with the conjuncture of the research market, i.e., gender programs are financed by international funds, and international research associations support this subject accordingly, to compensate for the insufficiency of budget financing. Thus, the Azerbaijan crisis institute of science is in "the hand" of international organizations and these institutions try to lead social science in a new direction using these international sources. Even conservatively thinking administrators confirm and support new programs which depend on the inflows of material resources in the education and research structures.

Organizational opportunities, creating conditions for institutionalization of new professions, are exceptionally important in the first stage. Formulating of the new educational structure creates a possibility for innovations. It is easy to submit new subjects in the frame of the new schools and education institutions. (Many universities include the new subjects, and Gender Studies is also included in the curriculum as one of the innovative subjects).

\section{Integration of Gender Studies into College and University Curricula}

Gender education recently became a concern of the Ministry of Education of Azerbaijan. Besides revising and approving curricula on different gender courses, now the Ministry has a focal point on gender issues. Within the ministerial structure a new position of Representative on Gender Issues was created, whose main mission is achievement of gender balance in the educational system.

The necessity of teaching Gender Studies as a subject came across at the time when fundamental reforms started to be carried out by the government of Azerbaijan in the education system. Formerly, Women's Studies was taught, but then it was considered as a separatist strategy and was substituted by Gender Studies. Why is there a need for Gender Studies as a science? As a continuation, another question appears: why do they study gender? 
1. To study permeating assumptions about women and men (masculinity and femininity), issues which lie on the heart of society and culture;

2. To investigate the importance of being born equal, versus of dominance related to gender, class, race, region, sexual orientation and ethnic, national or regional origin;

3. To develop ways of learning, teaching and living that enable adequate representation of the interests and aspirations of all people.

As in most CIS countries, in the Republic of Azerbaijan Gender Studies is also in the focus of some research centers. In universities it has been recently taught as a separate subject. Improvement in the field cannot be considered satisfactory, but some progress is observed. Taking into account that the majority of students at pedagogical universities are female, we perceive the urgency and importance of Gender Studies inclusion mainly into the curriculum of pedagogical universities.

The following directions should be taken into consideration during the implementation of Gender Studies as an academic program:

1. Teaching of special courses on gender problems;

2. Arranging students' of scientific-research work;

3. Publishing of methodological and scientific materials on gender issues;

4. Raising awareness of university professors on the problem of gender theory during methodological seminars;

5. Establishing gender-related literature libraries and so on.

Out of a total of 42 higher institutions in Azerbaijan, Gender Studies was introduced into the curriculum of 6 universities: Azerbaijan University of Languages, Baku State University, Academy of Public Administration under the President of the Republic of Azerbaijan, Baku Slavic University, Western University and Khazar University. The first four higher institutions have the status of state institutes, whereas the two latter are private universities. (Yuliya Gureyeva)

\section{Empirical studies of gender problems in the Azerbaijan education system}

In the narrow meaning of gender education it is teaching of gender problematic issues in different variants at social-humanitarian schools. In a more comprehensive sense, gender education gives the opportunity to form gender equality and overcome gender stereotypes. In this meaning, its existence in the specific education program is not the main requirement; carrying out the teaching of this subject as a part of higher education ideology is more important. 
For successful teaching of gender related subjects/courses at universities, first of all professors might highlight the issue of Gender Studies from different aspects of the science - Sociology, Psychology, History, Linguistics and so on - and the professors must be trained in advance. If one wishes to get education as a lawyer, manager, or philologist, they can easily find adequate universities. However, no one can find a specialized faculty or school of Gender Studies in Azerbaijan. Thus, it is time to train expedient staff for Gender Studies as a multidisciplinary subject. Today there is a large need for such staff in universities' labor market.

Here below, the results of empirical studies for the purpose of the gender conception description in the official education system of Azerbaijan are examined. A survey was conducted among university staff (various positions, mainly relevant professors were interviewed).

The main focus was put on the subject of gender studies and integration of this subject into the education system (and in the given situation, its integration into the university education system). What strategies are to be used for this integration? What strategies are to be used for gender conception integration? Should the teaching structure correlate with gender aspects? Do the professors who intend to teach Gender Studies need the primary effective preparation and qualification? Is there any agency engaging in the activity of teacher training for Gender Studies (supported by NGOs or without this support)? Is there any need for Gender Studies faculty in the universities of Azerbaijan? Probably the number of professors intending to teach Gender Studies in universities is not uncommon; unfortunately, it does not always give desirable results. Is there creative development of using resources for assistance of gender education for freshmen year students? What is the plan for intensifying and expanding the basis and position of gender conception on all levels of formal teaching? Consequently, we have analyzed the interviews to make conclusions. The notion of "Gender Studies" and "gender education", even for many university professors, is overcoming patriarchal arrangements and stereotypes. Meanwhile, professors interviewed comprehend that gender conception in education involves different sexes: peculiarities of physical and mental development and relevant problems of education. Here are some quotes from the interviews:

Interview (male professor): "The main idea consists of equality between women and men in the modern society i.e., equality of girls' and boys' rights for education. Our aim is to reveal their 'me'-conception and harmonious development. Gender stereotype is put as obstacle in the way of the new generation and it is fixed in our mind. The educating institutions, especially schools, as a product of our society naturally reproduce these stereotypes: a man is a head of 
the family, a breadwinner; a woman is a mother, proprietor, and delicate friend. Besides, not all women wish to be like this and not all men ideally come up to their sex".

Interview (female professor): "Male students are treated more carefully: they will soon find the work or go to serve in the Army... Boys are boys. But girls...They will not go to the Army, they hurry for marriage, they are frequently 'constrained', underestimated, generally, girls are given little or no notice".

What do the interviewees see in the capacity of gender conception in education?

Realization of the gender conception is as necessary as revising all teaching programs and selecting relevant personnel. Today teaching Gender Studies has not expanded very much. It is taught only in some large universities. Each of us understands that everything originates from sexual parity, and overcoming gender stereotypes is possible only by changing existing gender roles. Embedding gender culture is possible through education, instructing teachers, educators, tutors and even parents. It will be desirable if the government and society determine their position regarding this problem; it will be impetus for further discussion and research.

Much ambiguity still exits in gender education and it will be useful if it is carried out in the professional way. The main thing is society's interest in this problem. Gender education indispensably comes close to us, because the time demands very adequate answers for many unanswered questions.

\section{Education. Essence of Gender Aspects of Education in Contemporary Azerbaijan}

Education is one of the most important means of achieving gender equality and the development of women's rights opportunities. The Azerbaijani education system is governed by the Constitution, the laws on education, the program of reforms in the area of education, and other normative official acts. Article 42 of the Azerbaijan Constitution presents each citizen's education rights. Article 3 of Azerbaijan Republic Education Act ensures the citizens' education rights regardless of their sex.

Since the period of the Azerbaijani Enlightenment (the end of the 19th and beginning of the 20th centuries) and further in the course of the Soviet period, Azerbaijani society passed through an awkward route changing the traditional sexual stereotype in people's behaviors. The Soviet regime destroyed the 
foundations of traditional culture and this regime caused remarkable changes in Azerbaijani women's image and lifestyle: the successful process of women's unveiling, putting end to illiteracy, women's entry into the social-political sphere, and consequently, getting the possibility to work and subsequent financial independence. Since that time, female education became a synonym for modernization and progress. Unfortunately, when the topic is on the changing of women's gender stereotypes in the field of education, it is not definitely accepted by men.

At the present time the necessity of gender studies is the attempt to cognize the social process on the basis of changes of the social-cultural paradigm of behavior. Gender scrutinizes interconnection between social aspects of public morality and real factors of behavior which really formulates the contemporary society. Gender Studies is the attempt to look at new problems based on the principles such as how the changes of social-cultural identity lead to the transformation, generally, of social roles. Men and women are not determined because of their sexual criteria; now it is the actual process of formation of social status which determined individual opportunity in the field of education, occupational activity, and access to power, economy, education, policy, domestic role, reproductive behavior, etc. Hypothesis on the social status as the basic object of Azerbaijani "Gender Studies" permits us to review the role of the traditional feminist "biological-social" opposition for the post Soviet regime. In my country and in the West, "Gender Studies" is based on this discursive combination - inclusion of "social" and not denying "biological" factors. Impetuous changes happening in all fields of the cultural life of the society make the international scientific community approach to the assessment of harmony in the relations of sexes differently. Women's strengthened roles in social governance, in science, medicine, culture and art is so obvious that there is no need for proof.

\section{Gender Equity in the Education System}

Gender equity in education is one of the urgent requirements of the realization of the achievement of women's rights as a part of human rights. The education is not only personal advantage but also a vital prerequisite for the progress of the society. If in the society individual's intellectual development opportunity is lacking, the society is not able to be successfully developed and it is condemned to deterioration. Hence, the government as the reflector of general public concern is to be the official, institutional and material guarantee for getting a sound education of its citizens, regardless of their sexes, social positions, their living places and other distinctions. 
The final achievement of higher education is to build a new society where everybody is free of violence and exploitation. As to the education system, aspects related to male and female equity and as well as gender aspects are to be included into the curricula of the majority of subjects. Contribution to the development of Gender Studies should be not only as a field of science but also as a strategically important sphere in the direction of education and society reconstruction.

Gender equity in access to education can clearly help eliminate other forms of gender inequality, forming more egalitarian intra-family relations and increasing women's participation in social life.

Much value is placed upon human capital, and national wealth is approximately $70-80 \%$ in the developed countries, and it specifies intensive development of education not only for youth but also for adults. In the majority of the developed countries, women's rights are fixed by the legislation of the government, and in some countries even special programs are in place for involving women into universities and other academic institutes.

Even though in the Constitution of the Republic of Azerbaijan women's and men's equality is fixed and the government set forth an equal opportunity for getting education regardless of the sex of its citizens, women's educational resources are not still effectively used in the patriarchal Azerbaijan society. There are many barriers and reasons for the realization of women's potential. Education is the only possibility for women to increase their competitiveness in the labor market, although even well-educated women's salaries are usually less than men's salaries. In spite of women's high level of education and their professional experience they occupy more inferior positions and earn less salary in comparison with men. This phenomenon is described as institutional sexism. Although from the first day of its independence the Azerbaijan Government issued gender equity orders for the different fields of the society, the gender stereotypes existed and still exist in some fields (education included).

Institutional disproportion and social-economic consequence of the devaluation of women's human potential are not taken into consideration in the process of education reforms. Currently, the gender gap in the salary and professional segregation in the labor market afford poorly-educated men to achieve more than better-educated women. When we look at the following table we see a real danger for the growth of the gender imbalance in favor of men. 
Number of personnel staff of state higher educational institutions at the beginning of 2009/2010 academic years Sex distribution, as \% of total

\begin{tabular}{|l|c|c|}
\hline \multirow{2}{*}{} & \multicolumn{2}{|c|}{ Sex distribution } \\
\cline { 2 - 3 } & Women & Men \\
\hline Rectors & 8.6 & 91.4 \\
\hline Pro-rector, branch directors & 9.3 & 90.7 \\
\hline Heads of laboratories and units & 44.9 & 55.1 \\
\hline Faculty deans & 13.0 & 87.0 \\
\hline Departament heads & 19.6 & 80.4 \\
\hline Professors from departament staff & 14.7 & 85.3 \\
\hline Docents from departament staff & 33.1 & 66.9 \\
\hline Head teachers & 59.2 & 40.8 \\
\hline Teachers, assistants & 73.8 & 26.2 \\
\hline Total, \% & 47.9 & 52.1 \\
\hline
\end{tabular}

(See www.azstat.org/statinfo/demoqraphic/)

(This site may have inaccuracies.)

In spite of the fact that the education system is one of the most problematic spheres, gender problems in education are not still included into the agenda of political and professional discussions, and many of the contradictions of modern education are gender dimensions. Lack of official gender expertise for textbooks and manuals, acquisition of professional knowledge in the field of gender theory and methodology, and problems of including gender components into the government education standards have a serious impact on the quality of education. Thereby, existing systems for specialists' training contributes to the reproduction of gender stereotypes, and subsequently, it destructively influences specialists' worldviews and leading staffs' activities in the different government education spheres. It is perceptible that there is a lack of knowledge and interest in international experience applying analogical instruments on the level of assumption and realization of political decision. Experts suppose that in various cases (involving maternity, necessity of holding education and domestic commitment and so on), - women's outflow is from MA courses. Hence, by the enthusiasts' labor, research of gender problems of education produces appreciable thematic failure of social science. To date reasonably substantial and methodological materials have been accumulated, presenting interest for specialists in the field of education, academic institutions, as well as the public at large. 
The following publications represent the most interesting works of the Azerbaijan specialists investigating both general and gender problems of education and science: "Gender Aspect in the History of Azerbaijan", F. Mamedov, "Gender Aspects of Politology", F. Ordukhanov, "Gender aspects of the philosophy",

A. Azimov, "Gender Sociology", A. Akhundov, "Gender and Culture",

F. Farajova, "Gender: New stages of Women's Problems, "Gender Expertise of the Legislation of Azerbaijan", Ali Seid Abbas oglu, Rena Seid Rza gizi, "EthicGender Analyze of Social-Moral Behavior”, Kifayat Aghayeva and others).

Taking into consideration foreign readers' interest in this field of publications, some works have been translated into English. They can receive scientific information on the political and legal aspect of the gender relations in Azerbaijan ("Gender and Human Rights", "Gender: Woman and Politics", "Woman and Elections", "Woman and Prison", R. Mirzazadeh, "Gender: Issues of Ethics and Politics", I. Mammedzadeh, "Gender Aspects of the Economy", "Women Administrative Staff in Management", R. Ibrahimbeyli, "Some Aspects of Women's Employment in Azerbaijan", M. Mahmudov, M. Samedova, "Some Aspects of the Violence Against Women in Azerbaijan", Z. Seyfulla gizi, "The Parallel of State and Family Between Masculinity and Femininity", A. Asadov).

\section{Women in Science}

Science plays a valuable role in the life of the society. During long centuries, not only in my country but also all over the world, men dominated in science and education, despite the presence in these areas of a certain amount of women representing elite society. The same was true in Azerbaijan in the soviet, presocialist and in the contemporary periods of its development. During the Soviet regime, there were achievements overcoming of the gender imbalance in science and education. The steady implementation of the science and education development programs at the state level provided real opportunities for compulsory participation of both sexes (regardless of age, religion, nationality, social status, etc.) in the education process and in 1979 the population's illiteracy was put to an end all over the country.

Research and development (R\&D) have been a comparatively low priority for Azerbaijan in recent years, even falling from $0.34 \%$ of GDP in 2000 to just $0.17 \%$ in 2007. About one-fifth of R\&D is performed by the private sector. However, the country has a fairly strong scientific base on which to build: 1339 of every million 
inhabitants are researchers, a higher proportion than the world average of 1081 . Moreover, just under half (45\%) of researchers are women. In terms of scientific publications indexed in international journals, Azerbaijan has also increased its visibility in the Science Citation Index from 160 papers in 2000 to 292 in 2008. (Azerbaijan in reviewing its STI strategy, UNESCO/Natural Sciences, 2011)

Currently, the development of science and education and the attempts to achieve gender balance in this field might be the core of the concentration of the adequate Azerbaijani government officials. The right to intellectual property fixed in the Constitution (the Article 30.I, II) and the incentives for free enterprise (the Article 15.II) were comprehensively interpreted in private legislation (laws on science, education, culture, etc.), which is a legal basis for the further extensive development of the Republic of Azerbaijan in science and education.

From time to time negative attitudes toward women are met in science and education, and the development of science faces difficulties and obstacles that can be a real danger for their progressive development and even loss of the achievements gained over centuries.

However, it does not mean that Azerbaijani women do not play any role in the development of science. According to the statistic data of AR (Azerbaijan Statistic Committee, 2010) 48\% of all scientific workers are women. 9766 from 129001 women in the leading scientific-technical work are professional-researchers. 158 women of those hold a Doctor of Science degree, 2618 women hold a Doctor of Philosophy and 2 women are members of the Academy of Science.

The following table (The State Statistical Committee of the Republic of Azerbaijan, (see, www.azstat.org/statinfo/demoqraphic/, 2010) characterizes the dynamics of the gender development in the Azerbaijani science.

Scientific degree of the scientists trained as post-graduate students (at the beginning of the year)

\begin{tabular}{|l|l|l|l|l|}
\hline & \multicolumn{2}{|l|}{ Person } & \multicolumn{2}{l|}{ Sex distribution \% } \\
\cline { 2 - 5 } & Women & Men & Women & Men \\
\hline $\mathbf{2 0 0 5}$ & & & & \\
\hline doctors of science & 55 & 663 & 7.7 & 92.3 \\
\hline candidates of science & 24 & 114 & 17.4 & 82.6 \\
\hline $\mathbf{2 0 0 6}$ & & & & \\
\hline doctors of science & 78 & 797 & 8.9 & 91.1 \\
\hline
\end{tabular}




\begin{tabular}{|l|l|l|l|l|}
\hline candidates of science & 23 & 137 & 14.4 & 85.6 \\
\hline $\mathbf{2 0 0 7}$ & & & & \\
\hline doctors of science & 92 & 906 & 9.2 & 90.8 \\
\hline candidates of science & 33 & 150 & 18.0 & 82.0 \\
\hline $\mathbf{2 0 0 8}$ & & & & \\
\hline doctors of science & 97 & 990 & 9.7 & 90.3 \\
\hline candidates of science & 31 & 151 & 17.0 & 83.0 \\
\hline $\mathbf{2 0 0 9}$ & & & & \\
\hline doctors of science & 91 & 770 & 10.6 & 89.4 \\
\hline candidates of science & 46 & 125 & 26.9 & 73.1 \\
\hline $\mathbf{2 0 1 0}$ & & & & \\
\hline doctors of science & 97 & 707 & 12.1 & 87.9 \\
\hline candidates of science & 29 & 96 & 23.2 & 76.8 \\
\hline
\end{tabular}

(Candidate of science equals $\mathrm{PhD}$ )

Number of members (full) and corresponding members at the beginning of 2010 Number

\begin{tabular}{|l|l|l|}
\hline & Women & Men \\
\hline Members & 3 & 59 \\
\hline Correspondent members & 12 & 59 \\
\hline
\end{tabular}

(This may contain inaccuracies.)

The realities stated above of the present-day situation in the area of science show that there is no hope for either quick achievement of the gender balance or future achievement of the high level of the national science.

The women's declining economical stance in science causes growing gender disproportion. The difficultness of the female scientists' economic condition is verified by the reality to a larger extent of their lower salaries (unlike men, they cannot afford to work in several places). It is characterized by the main reasons:

1) A female scientist is not capable of paying for the services of a cleaning lady (engaging in the endless domestic responsibilities: doing laundry, cleaning the house, cooking, caring for the ill, very young and elderly members of the family, managing the home economy, etc.,) and

2) Scarcity of jobs for female scientists 
"You became a full professor at the same time you discovered you were about to become a mother. The biggest argument as to why academia is stacked against women is that the childbearing years coincide with those years in which you're busy compiling achievements, publishing articles, doing all those things that ensure that you'll get tenure. What were the decisions that factored into your choices, and how have you made it all work out?" (Linda Lowen, 2009)

\section{Conclusions}

Worldwide, women account for slightly more than a quarter of all scientific researchers - an increase compared to previous decades but still very far from parity (World's Women, United Nations New York, 2010)

Marginalization of women within academia or slow inclusion of women into the National Academia of the Republic of Azerbaijan is very serious problem raised by women researchers, but the situation remains unchanged. Nevertheless, cultural factors within academia are suggested as significant barriers: if male and female applicants are under evaluation for a $\mathrm{PhD}$ degree, male applicants are preferred. Women encounter specific difficulties in trying to earn a $\mathrm{PhD}$ degree or forging careers in academia. The process of earning $\mathrm{PhD}$ demands very important sacrifices; forcing someone to push forward, spend unlimited energy, make enduring efforts, and exclude private life (taking into consideration the patriarchal society in Azerbaijan, men could marry at any age without any problems, but even young women choose their partners for marriage from among those men who offer to marry them).

Many talented women have struggled for a doctoral degree and most of them could not complete it because of one reason, a "violence rule of the main gatekeepers" of academia who are inclined to preserve the ideals to authorize their positions.

There is a very popular saying in my country, "science is for a man, a woman's place is at home." This is the main mythology about an ideal Azerbaijani woman. Attitudes toward gender stereotypes might be changed by teaching and learning new gender roles and persuading people to abandon myths and misconceptions that restrict girls and women from fully participating in science. But this cultural change will become more possible with each educated girl and woman who challenges these myths and fallacies and stops them from being passed on to the next generation. 
Moreover, by establishing economic development and overall social progress, no country can afford to ignore gender inequality in science. To establish social justice is to establish gender equality. We must not forget that the chief contributors to change are the families, communities, school teachers, academic supervisors, and mentors of women scientists, the female scientists themselves and, unquestionably, responsible governmental officials. An army of female scientists, appropriately authorized, can direct their capacities towards their countries' development.

Better laws and improved policies might be effective to diminish gender inequality; altering traditional opinions about gender roles might be more significant in Azerbaijan. Practice confirms that in the most complicated issues the mechanism of equal rights does not work. Laws on paper are one thing, and real opportunities are different things (de jure versus de facto). Enhancing gender equality within a family without breaking intra-family order and national identity can be a challenge. Sound debates on gender attitudes among state, civil society, and mass media agencies can play a significant role in meeting this challenge.

Accordingly, intentional measures are sufficient to access the absolute equality in the democratic sovereign in the Republic of Azerbaijan. In viewing the fact of settled principles of the gender evolution in the contemporary Azerbaijani society, the indispensability of gender education improvement in Azerbaijan, gender science, as a result of gender propaganda, gender education and re-education of the society seem to be particularly bright. The actuality of research in the field of gender science - the science of the modern times in Azerbaijan is carried by the originality of the substance, its disputable traits and explicit conceptions, characteristics of the displaying of gender interactions and history of the social culture, the integrity between the theoretical direction of gender science and the practice of the social-cultural process of the society during the independence period of the Azerbaijani society. The cardinal duty for carrying out scientific research in the sphere of gender science was expected by the different representatives of science (the sociologists, culturologists, psychologists, political scientists, philosophers, physicians and other scientists).

Nonetheless, academia is still male-dominated but this dominance is seen as natural although Constitution forbids gender inequality in all field of the employment. Unfortunately, academia is not under the pressure of the relevant state organizations. This conception is open for construction and reconstruction in a continuing process.

"We cannot walk with one leg; we have to walk with both legs. Men and women have to be all given their rights, allowed to participate in building their societies, 
we are all humans, there are no divisions in humanity," (Abdulaziz Othman Altwaijri, 2011)

\section{References and Notes:}

1. Abdulaziz Othman Altwaijri, Azerbaijan - a forum for intercultural dialogue, See, www.euronews.net/2011/.../azerbaijan-a-forum-for-intercultural-dialogue, April 8, 2011

2. Ayfer Bartu, Halil Dundar, Geoff Howse, Larissa Lemberanskaya, Rasim Ramazanov, Rajab Sattarov, "Social Assessment. Azerbaijan Education Reform", final report, Baku, 2000

3. Asian Development Bank. Country Gender Assessment - Azerbaijan, 2005 Assisting Azerbaijan in reviewing its STI strategy, UNESCO/Natural Sciences, 24.03.2011,

4. Fidan Faradjeva, Magiba Aliyeva, "Gender Education in Azerbaijan", report, Baku, 2004

5.Phillipe Busquin, Gender and Excellence in the Making, Science and Society, European Communities, 2004

6. "Human Development Report 2009" .

7. Main Results of Household Budget Survey in 2005-2006. Baku

8. Linda Lowen, "Women and Science - A Scientific Approach to Family" / Career Balance Noted Female Scientist Says "Problem-Solve Using Your Good Science Mind", 2009

9. The State Statistical Committee of the Republic of Azerbaijan, See, www.azstat.org/statinfo/demoqraphic/)

10. UNESCO Science, Technology and Gender: An International Report

11. UNESCO Institute for Statistics Women in Science: Under-represented and undermeasured , 2006

12. United Nations Development Program, 2009

13. USAID. Gender Assessment in Azerbaijan. Baku, 2004.

14. Women and Men in Azerbaijan, State Statistical Committee of Azerbaijan Republic, 2010

15. World's Women, United Nations New York, 2010, Trends and Statistics, Department of Economic and Social Affair, 2010

16. Yuliya (Aliyeva) Gureyeva, National Status Report on Higher School Reforms and Gender Education in the Country, Baku, 2005

17. Yuliya (Aliyeva) Gureyeva, "Policy Attitude towards Women in Azerbaijan: Is Equality Part of the Agenda?" Gender Politics in the South Caucasus, 2010

18. www.gender-az,org

19. www.tqdk.gov.az

20. www.unesco.org/education/educprog/wche/declaration_eng.htm

21. Барчунова Т.В. “Эгоистичный гендер” или воспроизводство гендерной асимметрии в гендерных исследованиях, Общественные науки и современность, 2002, №5. C. 180-191

22. "Гендер: история, общество, культура. Гендер и повышение

образовательного уровня населения Азербайджана”, Баку-2002. Стр. 464-470 


\title{
Summary
}

\section{Women, Men and Education in Azerbaijan}

\author{
Kifayat Aghayeva
}

\author{
Azerbaijan University of Languages \\ Baku, Azerbaijan
}

Promoting of gender equality in science is a vital part of the European Union's research policy (Phillipe Busquin, 2004).

There is a very popular saying in my country, "science is for a man, a woman's place is at home." Many talented women have struggled for a doctoral degree and most of them could not complete it because of one reason, a "violence rule of the main gatekeepers" of academia who are inclined to preserve the ideals to authorize their positions.

As my research and teaching focus is gender, I always raise gender inequality problems in my scientific works. I have some articles dealing with marginalization of women within academia or slow inclusion of women into the National Academia of the Republic of Azerbaijan, but the situation remains unchanged. I show in my research how key positions are considered male-dominated in our academia and universities. Cultural factors within academia are suggested as significant barriers, so if male and female applicants are under evaluation for $\mathrm{PhD}$ degrees, male applicants are preferred.

Women encounter specific difficulties in trying getting $\mathrm{PhD}$ degrees or develop careers in academia. The process of earning $\mathrm{PhD}$ demands very important sacrifices; forcing someone to push forward, spend unlimited energy, make enduring efforts, and exclude private life (taking into consideration the patriarchal society in Azerbaijan, men could marry at any age without any problems, but even young women choose their partners for marriage from among those men who offer to marry them).

My analysis in this field supports the assumption that academia is still male-dominated but this dominance is seen as natural (The Republic of Azerbaijan Constitution forbids gender inequality). This conception is open for construction and reconstruction in a continuing process.

Key words: gender, science, education, gender inequality, Azerbaijan 